\title{
Pressure dependence of the silicon carbide synthesis temperature $\odot$
}

Cite as: J. Appl. Phys. 125, 165902 (2019); https://doi.org/10.1063/1.5085839

Submitted: 15 December 2018 . Accepted: 10 April 2019 . Published Online: 26 April 2019

S. Limandri, G. Garbarino (D), D. Sifre, M. Mezouar, and V. Galván Josa

\section{COLLECTIONS}

Note: This paper is part of the Special Topic on Ultra-Hard Materials.

F This paper was selected as Featured 


\title{
Pressure dependence of the silicon carbide synthesis temperature
}

\author{
Cite as: J. Appl. Phys. 125, 165902 (2019); doi: 10.1063/1.5085839 \\ Submitted: 15 December 2018 . Accepted: 10 April 2019. \\ Published Online: 26 April 2019
}

S. Limandri, ${ }^{1}$ G. Garbarino, ${ }^{2}$ (D) D. Sifre, ${ }^{2}$ M. Mezouar, ${ }^{2}$ and V. Galván Josa ${ }^{1, a)}$

\begin{abstract}
AFFILIATIONS
${ }^{7}$ Instituto de Física Enrique Gaviola, CONICET, Medina Allende y Haya de la Torre, Ciudad Universitaria CP 5000, Córdoba, Argentina

${ }^{2}$ European Synchrotron Radiation Facility, 71, avenue des Martyrs, CS 40220, 38043 Grenoble Cedex 9, France
\end{abstract}

Note: This paper is part of the Special Topic on Ultra-Hard Materials.

a)galvan@famaf.unc.edu.ar

\begin{abstract}
The starting temperature for $\mathrm{SiC}$ synthesis from elemental silicon, carbon black, and graphite powders was determined for pressures ranging from 0.8 to $11 \mathrm{GPa}$ by in situ X-ray diffraction experiments. The synthesized $\mathrm{SiC}$ corresponds to the cubic $3 \mathrm{C}$ phase with the presence of stacking faults along the [111] direction. The lowest density of the stacking faults is achieved when black carbon is used instead of graphite. The minimum temperature to start the $\mathrm{Si}+\mathrm{C} \rightarrow \mathrm{SiC}$ reaction slightly decreases when the pressure is increased up to $6 \mathrm{GPa}$ and the reaction begins before silicon melts. For pressures higher than $8 \mathrm{GPa}$, the starting temperature increases, and the formation of SiC from the SiII phase requires the complete melting of silicon. Bulk modulus $B_{o}=236(14) \mathrm{GPa}$ was obtained for the synthesized SiC phase.
\end{abstract}

Published under license by AIP Publishing. https://doi.org/10.1063/1.5085839

\section{INTRODUCTION}

Silicon carbide $(\mathrm{SiC})$ is a material with superior mechanical and physical properties: high mechanical strength, high hardness, good thermal conductivity, low density and thermal expansion, and resistance to oxidation, among others (Zhang et al., 2010). SiC ceramics have a wide range of applications in many fields such as semiconductor electronics, abrasives, heaters, and heat resistant structural materials.

Mineral SiC (moissanite), in its natural form, is extremely rare on our planet, so all the applications of $\mathrm{SiC}$ today use a synthetic material. $\mathrm{SiC}$ can be produced through many methods, but most of the $\mathrm{SiC}$ powder produced today is manufactured using the Acheson process, which includes carbothermal reduction of quartz by coke at about $2500-2700 \mathrm{~K}$ (Kumar and Gupta, 2002). Additives, such as $\mathrm{Y}_{2} \mathrm{O}_{3}, \mathrm{Al}_{2} \mathrm{O}_{3}, \mathrm{~B}, \mathrm{Fe}, \mathrm{HBO}_{3}$, and $\mathrm{NH}_{4}$, are used to accelerate the reaction rate, to decrease the reaction temperature, and to obtain controlled particle shapes (Guo et al., 2012). SiC crystallizes in many structural forms depending on the stacking sequence of $\mathrm{SiC}$ tetrahedral layers, the major polytypes being cubic $3 \mathrm{C}$ - and hexagonal $2 \mathrm{H}-, 4 \mathrm{H}$-, and $6 \mathrm{H}-\mathrm{SiC}$ structures. According to Larpkiattaworn et al. (2006), the reaction of silicon and carbon to form $\mathrm{SiC}$ has a negative free energy of formation at room temperature, whereas for silica $\left(\mathrm{SiO}_{2}\right)$ and carbon $(\mathrm{C})$, this value is large and positive, which implies that, theoretically, $\mathrm{SiC}$ can be formed at lower temperatures using the $\mathrm{Si}-\mathrm{C}$ reaction rather than using the $\mathrm{SiO}_{2}-\mathrm{C}$ reaction.

Interest in $\mathrm{SiC}$ lies not only in industrial applications. The studies of carbides are important in geosciences for understanding the carbon cycle and crust mantle interactions (Dobrzhinetskaya et al., 2018). Moreover, $\mathrm{SiC}$ is a candidate material to make up the interior of carbon-rich exoplanets (Daviau and Lee, 2017). The high carbon-to-oxygen ratios present on those planets would change the mineral phases precipitating from protoplanetary disks, i.e., carbides instead of silicates. Silicon carbide may be the abundant phase in the deep interiors of such planets. Understanding the structure and density of these planets depends on our comprehension of the high-pressure behavior (formation and stability) of $\mathrm{SiC}$ (Nisr et al., 2017). This knowledge would also help further develop $\mathrm{SiC}$ in nuclear, aerospace, and energy industries.

In this work, we performed experiments using a laser-heated diamond-anvil cell (DAC) and a Paris-Edinburgh (PE) cell, combined with in situ X-ray diffraction (XRD), to investigate the formation of $\mathrm{SiC}$ starting from the main constituents $\mathrm{Si}$ and $\mathrm{C}$ for pressures ranging from 0.8 to $11 \mathrm{GPa}$. 


\section{EXPERIMENTAL}

The starting materials were commercial high purity silicon powder Si (Sigma Aldrich, particle size $<45 \mu \mathrm{m}$, purity $99.5 \%$ ) and carbon from different sources: carbon black (Vulcan XC72) and graphite powder (Sigma Aldrich, particle size $<150 \mu \mathrm{m}$, purity 99.99\%). Powders were mixed in agate mortars with a molar Si:C ratio of 1:1.05 (for a silicon-carbon black mixture) and 1:1 (for a silicon-graphite mixture) using ethyl alcohol as a medium. An excess of carbon with respect to the stoichiometric $\mathrm{SiC}$ formula was used for silicon-carbon black samples in order to minimize the effect of agglomeration of nanoparticles in the mixing process. After mixing, samples were dried in a vacuum oven at $100{ }^{\circ} \mathrm{C}$ and were kept there until measurements were taken.

In situ X-ray diffraction measurements at 0.8 and $4 \mathrm{GPa}$ were performed using a large volume Paris-Edinburgh (PE) press VX5 type with WC anvils. Samples were placed in capsules of boron nitride (h-BN), which act as a pressure transmitting medium, with 1-mm-inner diameter $\times 1.5$-mm-inner length. The capsules were placed in a graphite heater with Mo caps to provide good thermal insulation and $\mathrm{MgO}$ rings to increase the stability of the cell assembly; and the whole furnace assembly was then placed inside a standard $7 \mathrm{~mm}$ boron-epoxy gasket with an outer polycarbonate plastic ring. A scheme of the cell assembly used for these experiments, along with the characteristic dimensions, can be observed in Fig. 1. Samples were compressed at room temperature up to the desired pressure and then heated by resistive heating at a rate of $10 \mathrm{~W} / \mathrm{min}$. Pressure and temperature were calculated from the X-ray diffraction patterns of silicon, h-BN, and $\mathrm{SiC}$ (when possible) through the many phases isochore method (Zhao et al., 1997).

For higher pressures $(5-11 \mathrm{GPa})$, in situ experiments were conducted using membrane-driving diamond-anvil cells (DACs) with diamond culet faces of $350-\mu \mathrm{m}$ diameter, Re preindented gasket foils (50- $\mu \mathrm{m}$ thickness and $150-\mu \mathrm{m}$ diameter), and air as a pressure transmitting medium. Pressure calibration was performed using the equation of state (EOS) of silicon. Heating was performed with double sided neodymium-doped yttrium aluminium garnet (Nd:YAG) lasers and temperature was determined by pyrometry (see Petitgirard et al., 2014 for more details). Table I summarizes experimental conditions and sample characteristics used in this work.

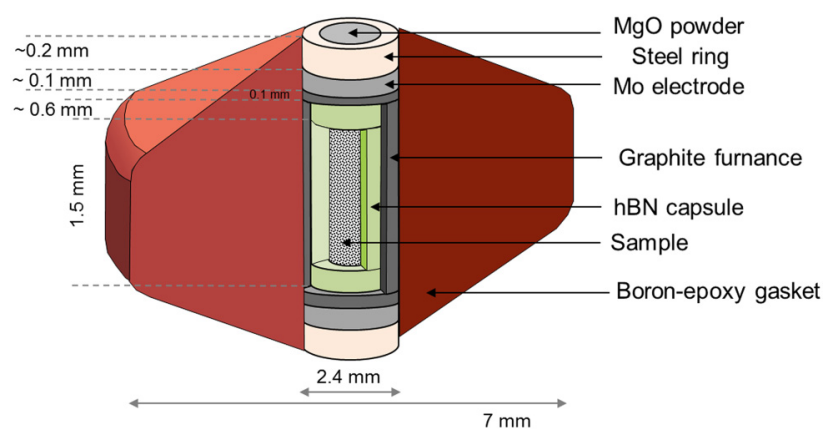

FIG. 1. Cell assembly for in situ synchrotron $\mathrm{X}$-ray experiments with the Paris-Edinburgh cell.
TABLE I. Sample characteristics and experimental details for the experiments performed in this work.

\begin{tabular}{|c|c|c|c|c|}
\hline $\begin{array}{l}\text { Sample } \\
\text { name }\end{array}$ & $\begin{array}{l}\text { Starting mixture, } \\
\text { Si:C molar ratio }\end{array}$ & $\begin{array}{l}\text { Pressure } \\
\text { cell }\end{array}$ & $\begin{array}{l}\text { Pressure } \\
(\mathrm{GPa})\end{array}$ & $\begin{array}{l}\text { Temperature } \\
\text { range }(\mathrm{K})\end{array}$ \\
\hline S3 & $\begin{array}{c}\mathrm{Si}+\text { carbon black } \\
1: 1.05\end{array}$ & PE & 4.0 & $300-1700$ \\
\hline S4 & $\begin{array}{c}\mathrm{Si}+\text { carbon black, } \\
1: 1.05\end{array}$ & $\mathrm{PE}$ & 0.80 & $300-1750$ \\
\hline S5 & $\mathrm{Si}+$ graphite, $1: 1$ & PE & 0.85 & $300-1880$ \\
\hline LTC11_1 & $\begin{array}{c}\mathrm{Si}+\text { carbon black, } \\
1: 1.05\end{array}$ & $\mathrm{DAC}$ & $1-8$ & $300-1800$ \\
\hline LTC15_2 & $\begin{array}{c}\mathrm{Si}+\text { carbon black, } \\
1: 1.05\end{array}$ & DAC & $8-11$ & $300-1700$ \\
\hline
\end{tabular}
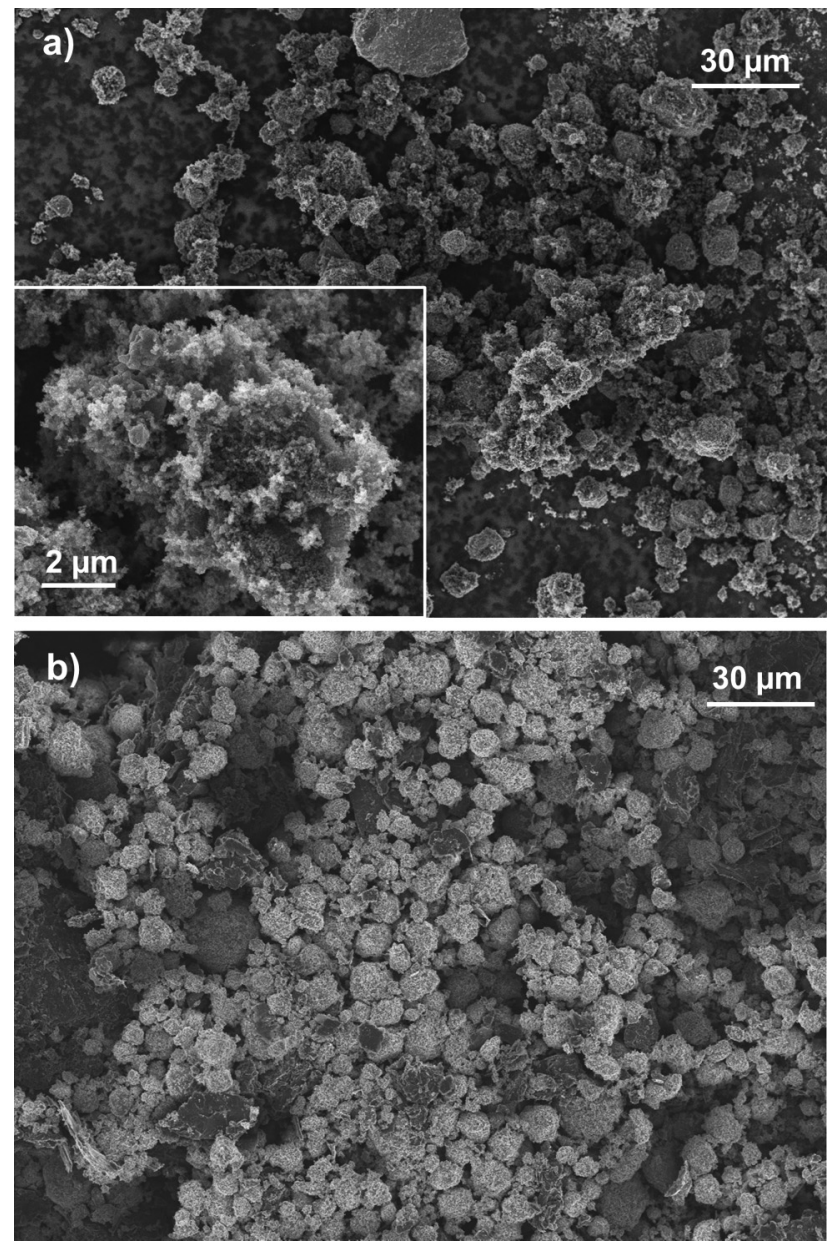

FIG. 2. SEM images of the starting mixtures: $\mathrm{Si}+$ black carbon (a); $\mathrm{Si}+$ graphite $(\mathrm{b})$. 
The experiments were performed at ID27 beamline, European Synchrotron Radiation Facility (ESRF, Grenoble, France) with monochromatic incident X-ray beam $(\lambda=0.3738 \AA$ ). Debye Scherrer rings were collected with a MAR345 image plate detector $(150 \mathrm{~mm}$ sample to detector distance) and with a MAR165 CCD circular (250 mm sample to detector distance) for PE and DAC experiments, respectively. A multichannel collimator (Morard et al., 2011) was used in PE experiments in order to reduce the X-ray background from the sample environment. The collected data were reduced and radially integrated over the rings by means of the DIOPTAS program (Prescher and Prakapenka, 2015). Powder diffraction patterns of $\mathrm{LaB}_{6}$ and $\mathrm{CeO}_{2}$ standards were used for calibrating the beam center, the detector tilt, and the sample to detector distance.

Micrographs and X-ray characteristic maps were acquired at Universidad Nacional de Córdoba, Argentina, with a scanning electron microscope (SEM) Eigma-Carl Zeiss with a Schottky electron gun. A silicon drifted X-ray detector with an $80 \mathrm{~mm}^{2}$ front area and a nominal resolution of $127 \mathrm{eV}$ for the $\mathrm{Mn}-\mathrm{K} \alpha$ line $(5.893 \mathrm{keV})$ was used to acquire X-ray maps and punctual spectra.

\section{RESULTS AND DISCUSSION}

SEM images corresponding to the starting mixtures can be observed in Fig. 2. Quasispherical silicon particles with diameters between 1 and $50 \mu \mathrm{m}$ and nanosized black carbon particles (graphite flakes) are clearly observed for $\mathrm{Si}+$ black carbon (graphite) mixtures. For the silicon + carbon black mixture, the silicon particles are surrounded by the nanosized carbon particles [see the inset in Fig. 2(a)], whereas for the silicon + graphite mixture, the particle sizes are similar.

Calibration temperature-powder and pressure-(force applied to the anvils) for samples S4 and S5 was performed by the isochore



FIG. 3. Calibration temperature-power (WK) for the PE cell. Black and gray solid circles correspond to the points obtained for S4 and S5 samples, respectively.

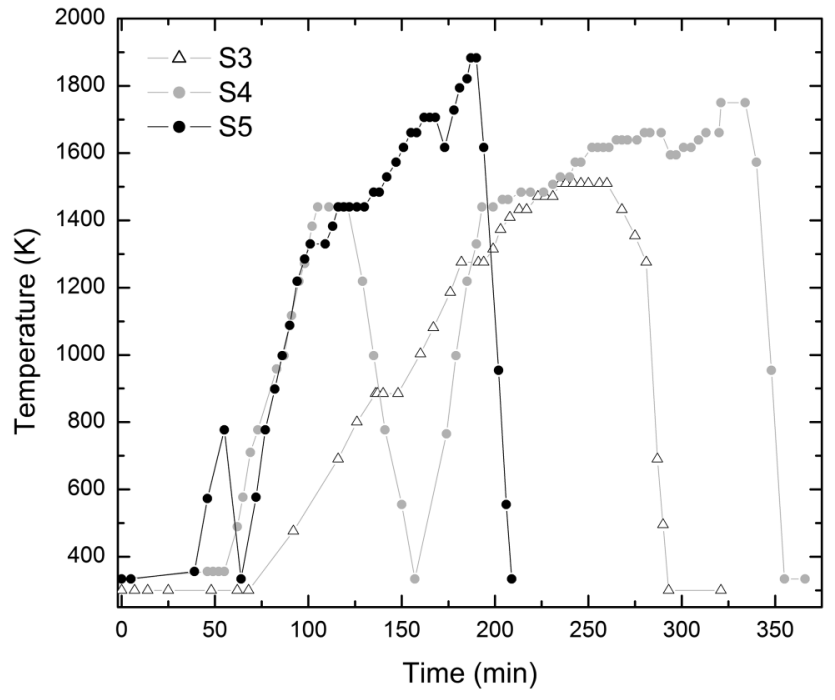

FIG. 4. Heat treatments applied to samples S3, S4, and S5 in the PE cell.

method. In this method, the unit cell volumes obtained from the $\mathrm{XRD}$ patterns for at least two phases are used to determine isochoric lines in the P-T space. Assuming that both phases are at the same temperature and pressure conditions, the isochoric lines must be intercepted in one point of the P-T space, giving the experimental values of pressure and temperature. The method works properly if phases have different slopes in their isochoric lines, i.e., different

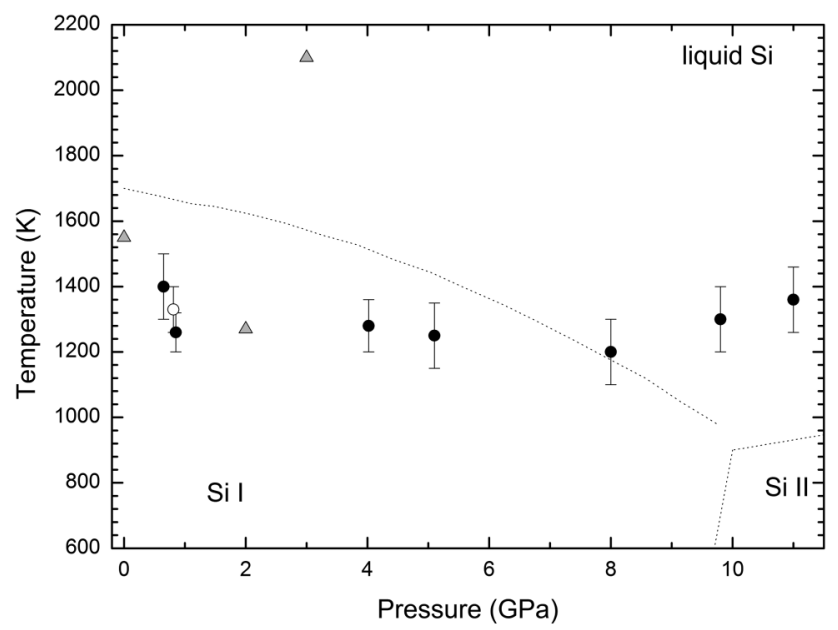

FIG. 5. Minimum temperature for the formation of $\mathrm{SiC}$ as a function of pressure. The results obtained in this work for silicon + carbon black (full circles) and silicon + graphite (hollow circle) starting mixtures; triangles: values reported by Bhaumik et al. (1999), Wang et al. (2006), and Larpkiattaworn et al. (2006) for $\mathrm{P}=3 \mathrm{GPa}, 2 \mathrm{GPa}$, and ambient pressure, respectively. The silicon phase diagram (Yang et al., 2004) is shown by the dotted line. 
thermal expansion and bulk modulus coefficients. We used Si and $\mathrm{h}-\mathrm{BN}$ phases to apply this method, and $\mathrm{SiC}$ when possible. The isochores were determined by the third order BirchMurnaghan equation of state (Birch, 1947) with thermoelastic parameters given by Watanabe et al. (2004) for the linear thermal expansion of silicon up to $1000 \mathrm{~K}$ (an extrapolation was performed for higher temperatures) and by Martinienseen and Warlimont (2005) for silicon bulk modulus and its derivative. Thermoelastic
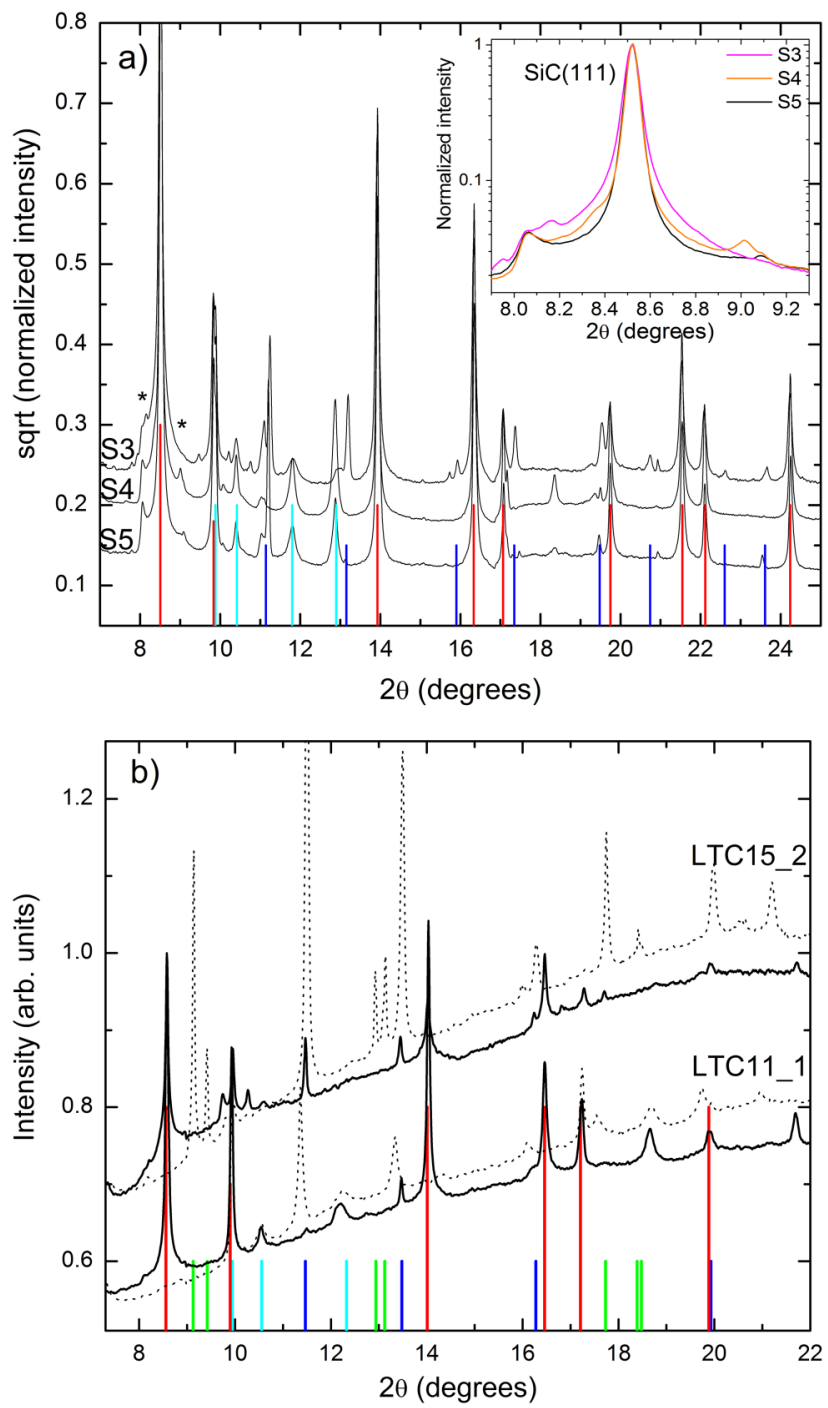

FIG. 6. (a) XRD patterns at ambient conditions after pressure and heat treatments for samples S3, S4, and S5. The inset is a zoom (at the logarithmic scale) for the $\mathrm{SiC}(111)$ region. Stars show the structures associated with the SF. (b) XRD patterns for samples LTC15 $2(9.8 \mathrm{GPa})$ and LTC11 $1(5.1 \mathrm{GPa})$ at $300 \mathrm{~K}$ (dotted line) and after temperature treatment (solid line) at $1400 \mathrm{~K}$ (for LTC15_2) and $1700 \mathrm{~K}$ (for LTC11_1). Vertical bars indicate the peak positions for SiC (red), Sil (blue), Sill (green), and BN (cyan). parameters given by LeGodec et al. (2000) and Wang et al. (2016) were used for $\mathrm{h}-\mathrm{BN}$ and for $\mathrm{SiC}$, respectively.

Figure 3 shows the temperature calibration curve obtained through the method abovementioned. Considering the uncertainties in the unit cell volume determination, the estimated error is $100 \mathrm{~K}$ for temperatures between 1000 and $2000 \mathrm{~K}$. The calibration obtained was applied to sample S3, since a direct application of the isochore method involves higher errors due to the fact that XRD
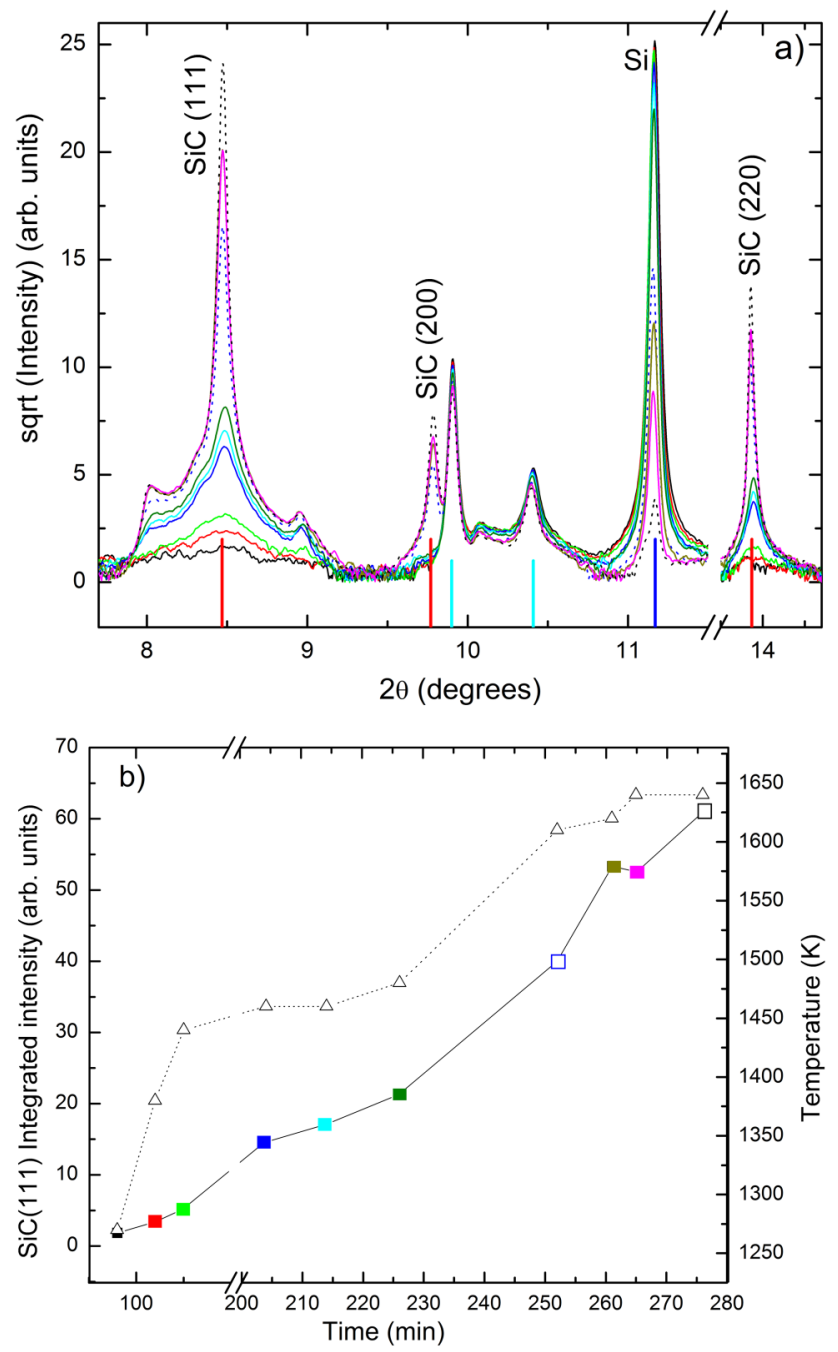

FIG. 7. Evolution of SiC phase for sample S4. (a) XRD patterns for different temperatures and times. Black line: $1270 \mathrm{~K}, 0 \mathrm{~min}$; red line: $1380 \mathrm{~K}, 102 \mathrm{~min}$; green line: 1440 K, 105 min; blue solid line: 1460 K, 214 min; cyan line: $1460 \mathrm{~K}$, $214 \mathrm{~min}$; olive line: $1480 \mathrm{~K}, 226 \mathrm{~min}$; blue dotted line: $1610 \mathrm{~K}, 252 \mathrm{~min}$; dark yellow line: $1620 \mathrm{~K}, 26 \mathrm{~min}$; magenta line: $1640 \mathrm{~K}, 265 \mathrm{~min}$; black dotted line: $1640 \mathrm{~K}, 276 \mathrm{~min}$. Vertical bars indicate the peak positions for SiC (red), Sil (blue), and $\mathrm{BN}$ (cyan). (b) SiC(111) integrated peak intensity (squares) and the corresponding temperature (triangles) as a function of time are shown. The same color scheme is used for diffraction patterns and $\mathrm{SiC}(111)$ integrated peak intensity. 
peaks are wider and overlapped in this case. Pressures determined for these samples yielded $(0.80 \pm 0.10) \mathrm{GPa}$ for S4, $(0.85 \pm 0.10) \mathrm{GPa}$ for S5, and (4.0 \pm 0.5$) \mathrm{GPa}$ for S3.

The temperature treatments applied to the samples in the PE cell are shown in Fig. 4. In all cases, the temperature was increased up to the beginning of $\mathrm{SiC}$ reaction. After this, the system was kept in this condition for a few minutes to study the reaction rate. Then, the temperature was slightly increased and kept a few minutes more at that level. The process was repeated 3 or 4 times, and then the sample was quenched to room temperature by turning off the electrical power.

For DAC experiments, the pressure was calibrated by the EOS of silicon. Once the desired pressure was achieved, laser heating was applied in a small sample region raising the laser power up to the formation of $\mathrm{SiC}$. The experiment was repeated in another sample region not affected by heat.
The temperature at which the reaction $\mathrm{Si}+\mathrm{C} \rightarrow \mathrm{SiC}$ starts was determined by observing the appearance of the $\mathrm{SiC}(111)$ peak in the XRD patterns. This temperature, as a function of pressure, is shown in Fig. 5, along with data reported by other authors for similar reactions. The pressure and temperature for the formation of $\mathrm{SiC}$ is within the experimental uncertainties for S4 and S5 samples, that is to say, the formation of $\mathrm{SiC}$ starts at almost the same temperature, regardless of the carbon phase. The minimum temperature for the synthesis of $\mathrm{SiC}$ slightly decreases when increasing the pressure up to $6 \mathrm{GPa}$ and increases for pressures higher than $8 \mathrm{GPa}$. The formation of $\mathrm{SiC}$ from SiII seems to be unfavorable in terms of temperature, since it requires the complete fusion of silicon to start the $\mathrm{SiC}$ formation.

According to the XRD patterns, the synthesized $\mathrm{SiC}$ corresponds to the cubic $3 \mathrm{C}$ phase and presents stacking faults (SF), which are evidenced in the structure of the $\mathrm{SiC}(111)$ peak (see Fig. 6).
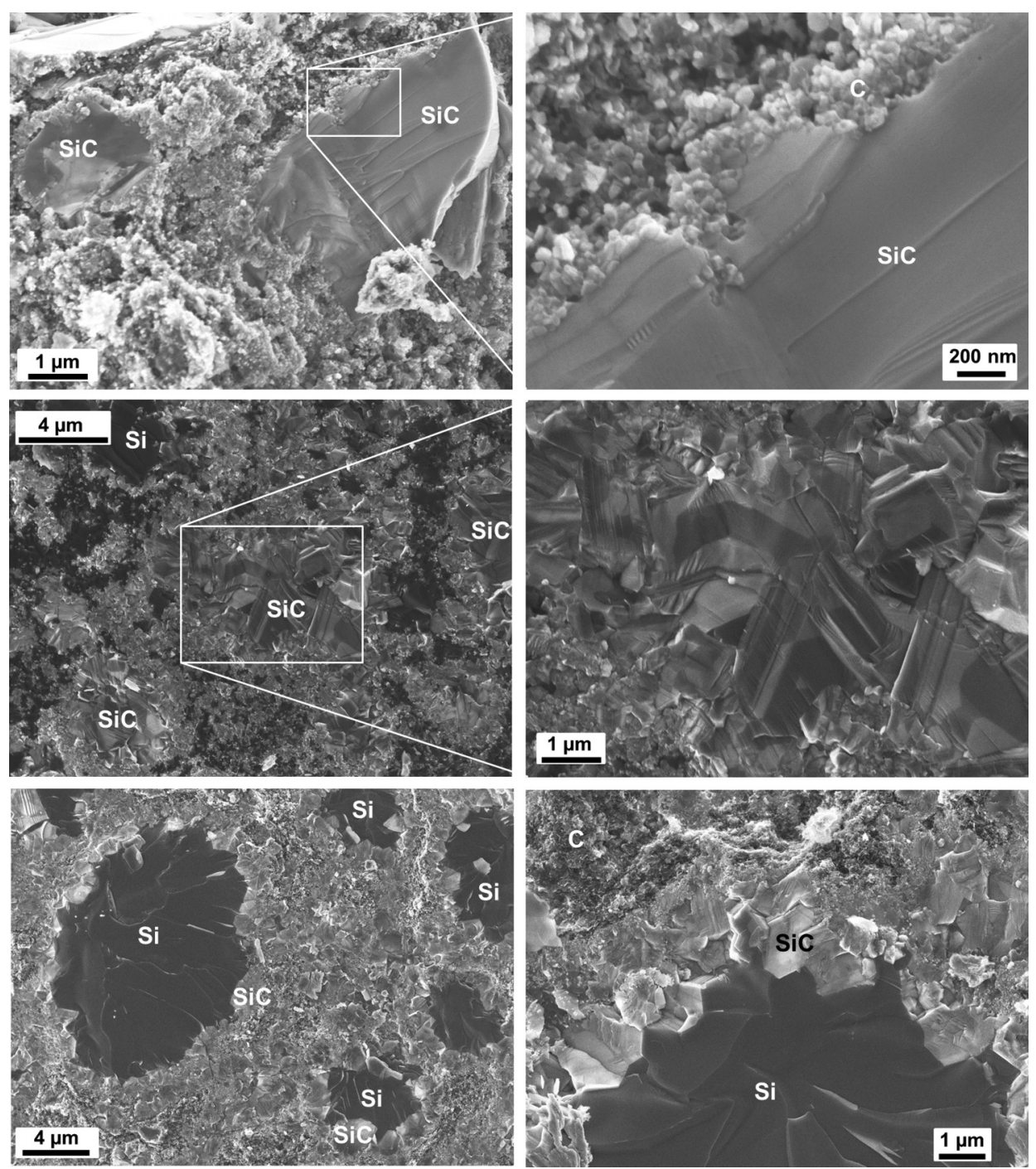

FIG. 8. SEM micrographs corresponding to samples S4 (up), S5 (middle), and S3 (down) at room conditions after the thermal treatments. Figures at the right correspond to high magnification images of regions presenting SiC. 
Crystallite sizes for the SiC phase in samples S3, S4, and S5, estimated from the $\mathrm{SiC}(220)$ peak width by the Scherrer formula are, respectively, $270 \pm 9,390 \pm 10$, and $329 \pm 10 \AA$. For these calculations, the instrumental contribution to the peak width, estimated from the Rietveld refinement of the $\mathrm{LaB}_{6}$ diffraction pattern acquired in the same experimental conditions, was removed and the remaining width was completely associated with the crystalline domain size. The contribution of the strain effects to the peak width is minimized by using a low angle peak. The intensity ratio between the structure at $8.05^{\circ}$ (due to the SF) and the $\mathrm{SiC}(200)$ peak is proportional to the SF density (Seo et al., 1991) and yields $0.48 \pm 0.09,0.15 \pm 0.08$, and $0.27 \pm 0.08$ for samples S3, S4, and S5, respectively. The high SF density and low crystallite size of S3 could be related to the incomplete $\mathrm{Si}+\mathrm{C} \rightarrow \mathrm{SiC}$ reaction. The higher crystallite size and the lower SF density of S4 compared to S5 (both samples were at almost the same pressure) are due to better carbon mobility in black carbon than in graphite. For DAC experiments, the crystallite domain sizes are $310 \pm 25$ and $200 \pm 20 \AA$, whereas the SF density is $0.12 \pm 0.06$ and $0.69 \pm 0.06$ for samples LTC11_1 and LTC15_2, respectively. As can be observed from DAC and PE experiments, the higher the crystalline domains, the lower the SF density.

$\mathrm{SiC}$ formation starts before silicon melting for $\mathrm{P}<4 \mathrm{GPa}$. Nevertheless, at minimum temperature, the reaction is very slow, and it is limited at the surface of the reactants. Silicon reacts with solid carbon, forming nuclei of $\mathrm{SiC}$ at the interface, probably at defect sites (Wieligor et al., 2005). Since diffusion is very low (the silicon is not melted), the $\mathrm{SiC}$ grains form a core around the silicon particles, which separates Si from C (see Fig. 8).
The diffusion of $\mathrm{C}$ is lower in $\mathrm{SiC}$ than that of $\mathrm{Si}$; consequently, the $\mathrm{SiC}$ formation becomes slower. The effect is countered when the temperature is increased. For example, Fig. 7 shows the evolution of $\mathrm{SiC}$ peaks for sample $\mathrm{S} 4(0.8 \mathrm{GPa})$.

As can be observed in Fig. 6(a), silicon was completely transformed in sample S4, whereas in sample S5, there is a reminder; despite this, the latter sample achieved a higher maximum temperature, and both experiments were performed at the same pressure. This means that the diffusion process involved in the $\mathrm{SiC}$ formation is enhanced when nanosized carbon particles are used instead of graphite flakes. As observed by other authors (Bhaumik et al., 1999; Wieligor et al., 2005; and Wang et al., 2006), less crystalline and small size reactant powders enhance $\mathrm{SiC}$ formation, and this is related to the lower activation energy for the formation of $\mathrm{SiC}$ when nanosized carbon was used instead of graphite or diamond carbon (Wang et al., 2006).

SEM micrographs of the samples at room conditions after the treatments are shown in Fig. $8 . \mathrm{SiC}, \mathrm{Si}$, and $\mathrm{C}$ phases were identified in the images with the aid of X-ray spectra for the bulk samples S3, S4, and S5 (PE experiments). Nanosized carbon is present around $\mathrm{SiC}$ particles for $\mathrm{S} 4$, whereas tilelike $\mathrm{SiC}$ agglomerates can be observed in S5. In the case of the S3 sample, SiC phase is observed around silicon particles for the S3 sample (see Fig. 9), which corroborates the $\mathrm{SiC}$ growing kinetics abovementioned. According to X-ray emission spectra acquired in punctual zones, gray color variations in $\mathrm{SiC}$ regions do not correspond to changes in mass concentrations; they could correspond to variations in the crystalline orientation. SiC crystals are more faceted and sharp for the S5 sample.
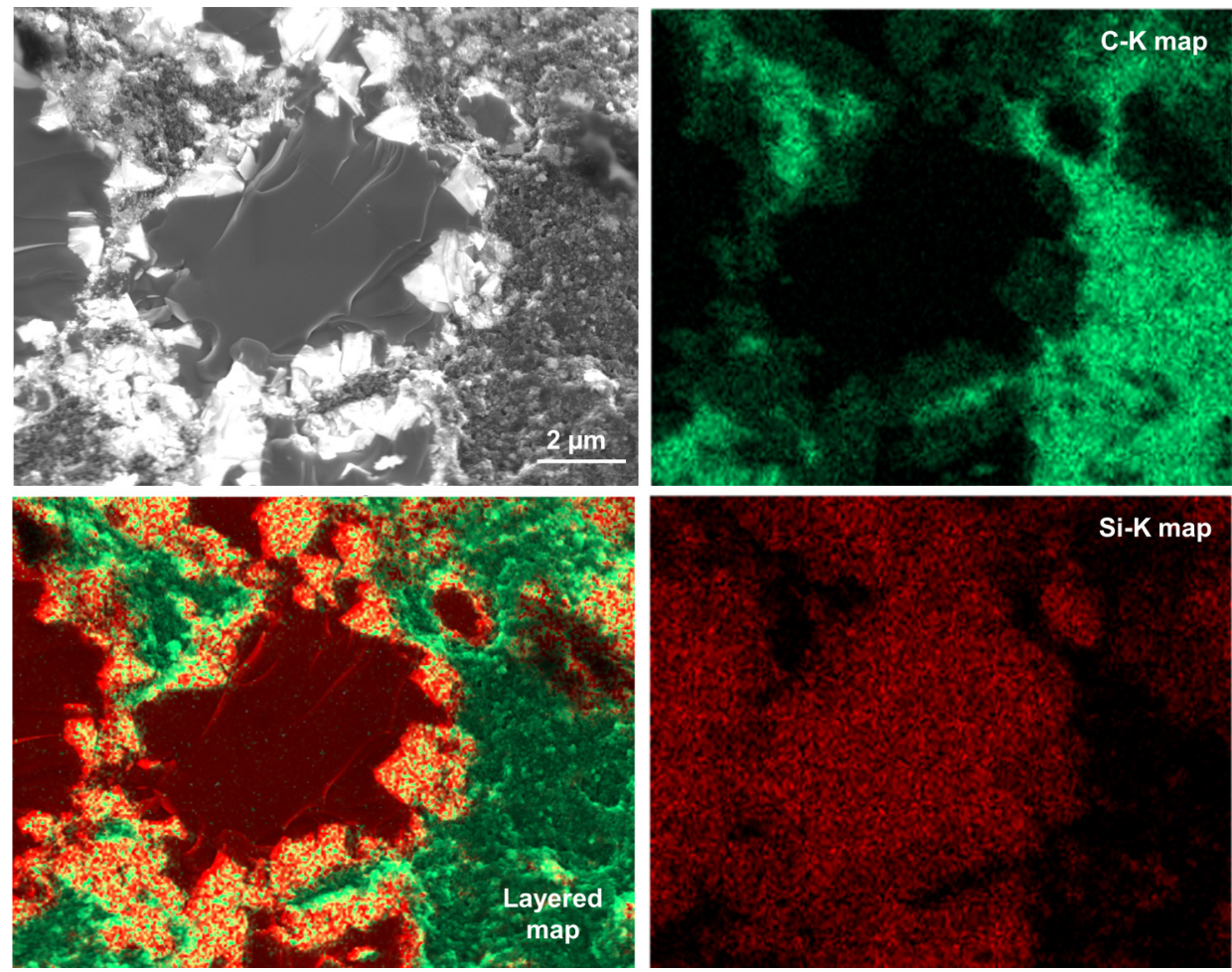

FIG. 9. SEM micrographs and X-ray maps for sample S3. Regions rich in $\mathrm{Si}$ and $\mathrm{C}$, associated with the SiC phase, are clearly identified in the layered image (yellow + red zone). 


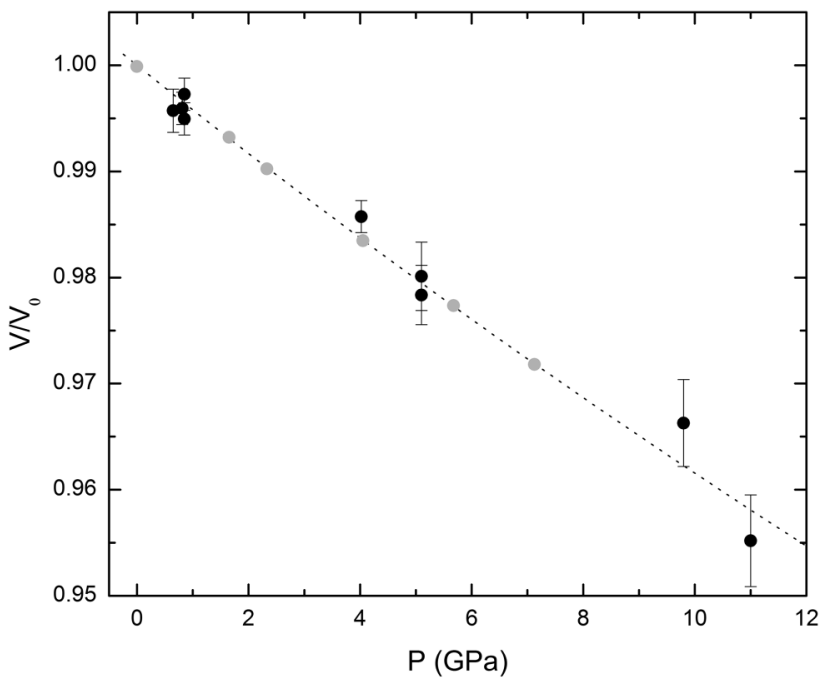

FIG. 10. Volume per atom for the synthesized $3 \mathrm{C}$-SiC phase as a function of pressure. The present results (black dots) and the corresponding fit with a third order Birch-Murhanghan EOS (dotted line) and experimental results obtained by Wang et al. (2016) (gray dots).

Stacking faults are also observed in the SEM images. Identifying phases in the SEM micrographs of samples obtained from DAC experiments is difficult due to the small region where the thermal treatment was performed (a few micrometers) and the presence of $\mathrm{BN}$ coming from the diamond isolation.

Figure 10 shows the volume per atom obtained from Rietveld refinement of the XRD patterns for the synthesized 3C-SiC phase as a function of pressure at room temperature. These data were fitted with a third order Birch-Murnaghan equation of state, obtaining a bulk modulus of $\mathrm{B}_{\mathrm{o}}=236 \pm 14 \mathrm{GPa}$ and a volume at zero pressure of $\mathrm{V}_{0}=20.77 \pm 0.03 \AA^{3}$. For the fitting, the derivative of the bulk modulus was fixed to 4 (Wang et al., 2016), since the amount of data was not enough to refine all the parameters involved. The values obtained from the fits are similar to those reported by Wang et al. (2016): $\mathrm{B}_{\mathrm{o}}=237 \pm 2 \mathrm{GPa}, \mathrm{V}_{0}=20.710 \pm 0.002 \mathrm{~A}^{3}$.

\section{CONCLUSION}

$\mathrm{SiC}$ was synthesized by heating mixtures of $\mathrm{Si}$ and carbon black or graphite in the pressure and temperature ranges from 0.8 to $11 \mathrm{GPa}$ and from 1200 to $1400 \mathrm{~K}$, respectively. The evolution of phases was studied using the laser-heated diamond-anvil cell and the Paris-Edinburgh cell, combined with in situ X-ray diffraction, which allowed us to obtain the minimum temperature necessary to start the $\mathrm{Si}+\mathrm{C} \rightarrow \mathrm{SiC}$ reaction. The synthesized $\mathrm{SiC}$ corresponds to the cubic 3C phase with micrometric sized grains and presents stacking faults along the [111] direction.

$\mathrm{SiC}$ formation starts before silicon melting at the siliconcarbon interface for pressures lower than $6 \mathrm{GPa}$. It starts with a $\mathrm{SiC}$ shell formed around silicon particles. To keep the reaction going, rising temperature becomes necessary. This allows diffusion processes through the $\mathrm{SiC}$ shell.
For the same pressure, even when the formation of $\mathrm{SiC}$ starts at almost the same temperature, the final temperature required for completing the reaction is lower when using carbon black than when using graphite as the starting material. Nanosized and low crystallinity carbon particles allow a better diffusion of carbon into $\mathrm{Si}$ and yield $\mathrm{SiC}$ with a low SF density. The SiC bulk modulus obtained from the EOS is in good agreement with data reported in the literature for the $3 \mathrm{C}-\mathrm{SiC}$ phase.

\section{ACKNOWLEDGMENTS}

We would like to thank the ESRF (ID27 beamline) for providing in-house time to undertake these investigations and CONICET (Argentina) for financing the postdoctoral research stays of S.L. and V.G.J.

\section{REFERENCES}

Bhaumik, S. K., Divakar, C., Usha Devi, S., and Singh, A. K., "Synthesis and sintering of $\mathrm{SiC}$ under high pressure and high temperature," J. Mater. Res. 14, 906-911 (1999).

Birch, F., "Finite elastic strain of cubic crystal," Phys. Rev. 71, 809-824 (1947).

Daviau, K. and Lee, K. K. M., "Zinc-blende to rocksalt transition in SiC in a laser-heated diamond-anvil cell," Phys. Rev. B 95, 1134108 (2017).

Dobrzhinetskaya, L., Mukhin, P., Wang, Q., Wirth, R., O’Bannone, E., Zhao, W., Eppelbaum, E., and Sokhonchuk, T., "Moissanite $(\mathrm{SiC})$ with metal-silicide and silicon inclusions from tuff of Israel: Raman spectroscopy and electron microscope studies," Lithos 310-311, 355-368 (2018).

Guo, X., Zhu, L., Yang, H., and Zhang, L., "Effects of additives on the microstructure of synthesized $\mathrm{SiC}$ particles by using silica sol/bamboo charcoal system," Mater. Lett. 73, 133-135 (2012).

Kumar, V. P. and Gupta, G. S., "Study of formation of silicon carbide in the Acheson process," Steel Res. 73, 31-38 (2002).

Larpkiattaworn, S., Ngernchuklin, P., Khongwong, W., Pankurddee, N., and Wada, S., "The influence of reaction parameters on the free $\mathrm{Si}$ and $\mathrm{C}$ contents in the synthesis of nano-sized SiC," Ceram. Int. 32, 899-904 (2006).

Le Godec, Y., Martinez-Garcia, D., Mezouar, M., Syfosse, G., Itié, J.-P., and Besson, J. M., "Thermoelastic behaviour of hexagonal graphite-like boron nitride," High Press. Res. 17, 35-46 (2000).

Morard, G. G., Mezouar, M., Bauchau, S., Álvarez-Murga, M., Hodeau, J. L., and Garbarino, G., "High efficiency multichannel collimator for structural studies of liquids and low-Z materials at high pressures and temperatures," Rev. Sci. Instrum. 82, 023904 (2011).

Nisr, C., Meng, Y., MacDowell, A. A., Yan, J., Prakapenka, V., and Shim, S.-H., "Thermal expansion of $\mathrm{SiC}$ at high pressure-temperature and implications for thermal convection in the deep interiors of carbide exoplanets," J. Geophys. Res. Planets 122, 124-133 (2017).

Petitgirard, S., Salamat, A., Beck, P., Weck, G., and Bouvierf, P., "Strategies for in situ laser heating in the diamond anvil cell at an X-ray diffraction beamline," J. Synchrotron Radiat. 21, 89-96 (2014).

Prescher, C. and Prakapenka, V. B., "DIOPTAS: A program for reduction of two-dimensional X-ray diffraction data and data exploration," High Press. Res. 35, 223-230 (2015).

Seo, W.-S., Pai, C.-H., Koumoto, K., and Yanagida, H., "Microstructure development and stacking fault annihilation in $\beta$-SiC powder compact," J. Ceram. Soc. Jpn. 99, 443-447 (1991).

Springer Handbook of Condensed Matter and Materials Data, edited by Martinienseen, W. and Warlimont, H. (Springer, 2005), Series ISSN 2522-8692.

Wang, Y., Liu, Z. T. Y., Khare, S. V., Collins, S. A., Zhang, J., Wang, L., and Zhao, Y., "Thermal equation of state of silicon carbide," Appl. Phys. Lett. 108, 061906 (2016). 
Wang, Y., Voronin, G. A., Zerda, T. W., and Winiarski, A., "SiC-CNT nanocomposites: High pressure reaction synthesis and characterization," J. Phys. Condens. Matter 18, 275-282 (2006).

Wang, Y. and Zerda, T. W., "The mechanism of the solid-state reaction between carbon nanotubes and nanocrystalline silicon under high pressure and at high temperature," J. Phys. Condens. Matter 18, 2995-3003 (2006).

Watanabe, H., Yamada, N., and Okaji, M., "Linear thermal expansion coefficient of silicon from 293 to $1000 \mathrm{~K}$,” Int. J. Thermophys. 25, 221-236 (2004).

Wieligor, M., Wang, Y., and Zerda, T. W., "Raman spectra of silicon carbide small particles and nanowires," J. Phys. Condens. Matter 17, 2387-2395 (2005).
Yang, C. C., Li, J. C., and Jiang, Q., "Temperature-pressure phase diagram of silicon determined by Clapeyron equation," Solid State Commun. 129, 437-441 (2004).

Zhang, H., Ding, W., He, K., and Li, M., "Synthesis and characterization of crystalline silicon carbide nanoribbons," Nanoscale Res. Lett. 5, 1264-1271 (2010).

Zhao, Y., Von Dreele, R. B., Weidner, D. J., and Schiferl, D., "P-V-T data of hexagonal boron nitride $\mathrm{h}-\mathrm{BN}$ and determination of pressure and temperature using thermoelastic equations of state of multiple phases," High Press. Res. 15, 369-386 (1997). 